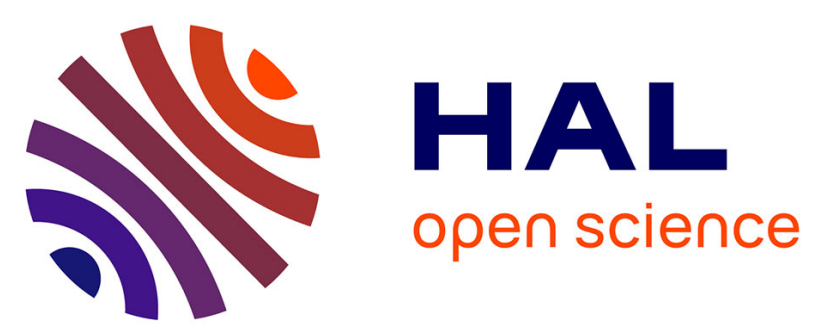

\title{
Dynamics of GH secretion during incremental exercise in obesity, before and after a short period of training at different work-loads
}

\author{
Alberto Salvadori, Paolo Fanari, Paolo Marzullo, Franco Codecasa, Ilaria \\ Tovaglieri, Mauro Cornacchia, Gillian E Walker, Amelia Brunani, Erminio \\ Longhini
}

\section{To cite this version:}

Alberto Salvadori, Paolo Fanari, Paolo Marzullo, Franco Codecasa, Ilaria Tovaglieri, et al.. Dynamics of GH secretion during incremental exercise in obesity, before and after a short period of training at different work-loads. Clinical Endocrinology, 2010, 10.1111/j.1365-2265.2010.03837.x . hal-00552613

\section{HAL Id: hal-00552613 \\ https://hal.science/hal-00552613}

Submitted on 6 Jan 2011

HAL is a multi-disciplinary open access archive for the deposit and dissemination of scientific research documents, whether they are published or not. The documents may come from teaching and research institutions in France or abroad, or from public or private research centers.
L'archive ouverte pluridisciplinaire HAL, est destinée au dépôt et à la diffusion de documents scientifiques de niveau recherche, publiés ou non, émanant des établissements d'enseignement et de recherche français ou étrangers, des laboratoires publics ou privés. 


\section{Dynamics of GH secretion during incremental exercise in obesity, before and after a short period of training at different work-loads}

\begin{tabular}{|c|c|}
\hline Journal: & Clinical Endocrinology \\
\hline Manuscript ID: & CEN-2009-000870.R3 \\
\hline Manuscript Type/Office: & 1 Original Article - UK/Europe \\
\hline $\begin{array}{r}\text { Date Submitted by the } \\
\text { Author: }\end{array}$ & 05-May-2010 \\
\hline Complete List of Authors: & $\begin{array}{l}\text { Salvadori, Alberto; Istituto Auxologico Italiano, Respiratory } \\
\text { Rehabilitation } \\
\text { Fanari, Paolo; Istituto Auxologico Italiano, Respiratory } \\
\text { Rehabilitation } \\
\text { Marzullo, Paolo; University of Piemonte Orientale, Dep. Of Clinical } \\
\text { and Experimental Medicine } \\
\text { Codecasa, Franco; Istituto Auxologico Italiano, Respiratory } \\
\text { Rehabilitation } \\
\text { Tovaglieri, Ilaria; Istituto Auxologico Italiano, Respiratory } \\
\text { Rehabilitation } \\
\text { Cornacchia, Mauro; Istituto Auxologico Italiano, Respiratory } \\
\text { Rehabilitation } \\
\text { Walker, Gillian E; Istituto Auxologico Italiano, Chemical Laboratory } \\
\text { Brunani, Amelia; Istituto Auxologico Italiano, Rehabilitation } \\
\text { Medicine } \\
\text { Longhini, Erminio; Istituto Auxologico Italiano, Respiratory } \\
\text { Rehabilitation }\end{array}$ \\
\hline Key Words: & Obesity, GH, Training, Anaerobic threshold, Pituitary \\
\hline
\end{tabular}


Dynamics of GH secretion during incremental exercise in obesity, before and after a short period of training at different work-loads

Short title: GH during exercise in obesity: effects of different training

Alberto Salvadori*, Paolo Fanari*, Paolo Marzullo ${ }^{* *}$, Franco Codecasa*, Ilaria Tovaglieri*, Mauro Cornacchia*, Gillian Walker^, Amelia Brunani ${ }^{\circ \circ}$, Erminio Longhini*

* Division of Respiratory Rehabilitation, H. San Giuseppe, Istituto Auxologico Italiano

- Department Of Clinical and Experimental Medicine, University of Piemonte Orientale “A. Avogadro", Novara,

** Division of General Medicine, H. San Giuseppe, Istituto Auxologico Italiano

^ Laboratory of Pediatrics, University of Piemonte Orientale “A. Avogadro”, Novara,

${ }^{\circ}$ Division of Rehabilitation Medicine, H. San Giuseppe, Istituto Auxologico Italiano

Correspondence:

Paolo Fanari,

Istituto Auxologico Italiano

P. O. Box N. 1

I - 28921- Verbania (VB), Italy

Fax: +39323514411

Email: rehab.med@auxologico.it

Keywords: obesity, GH, training, anaerobic threshold

Acknowledgements. We thank dr. Clotilde De Medici and Fabiola Belardi for their assistance in managing this study. We declare no conflict of interest specific to this manuscript. 
Word count: 3118 words

\section{Summary}

Background. Growth hormone $(\mathrm{GH})$ is normally sensitive to physical exercise. Intensity and duration of exercise, fitness as well as age, all can influence GH response to exercise. In obesity, $\mathrm{GH}$ secretion is decreased both in basal conditions and in response to exercise.

Objective. To analyze the dynamics of $\mathrm{GH}$ response to a progressive cycloergometric test conducted up to exhaustion in adult normal subjects and obese patients, after a reconditioning program at different workloads.

Design and methods. We studied 8 lean subjects (4 males, mean age 34.3 yrs, range $26-47$ yrs, mean BMI $22.1 \mathrm{~kg} / \mathrm{m}^{2}$ ). GH was sampled at baseline and during the last $30 \mathrm{~s}$ of each power output increase. Anaerobic threshold (AT) was detected by the V-slope method. The same test was carried out in 16 obese subjects ( 7 males, mean age $39.1 \mathrm{yrs}$, range $20-59 \mathrm{yrs}$, mean BMI $35.8 \mathrm{~kg} / \mathrm{m}^{2}$ ) and repeated after a 4-week reconditioning program consisting of aerobic workout (Group A, 8 subjects, 3 males, mean age 40.5 yrs, range 22-59 yrs, mean BMI $33.6 \mathrm{~kg} / \mathrm{m}^{2}$ ), and aerobic plus anaerobic work (group B, 8 subjects, 4 males, mean age 37.6 yrs, range 20-56 yrs, mean BMI $38.0 \mathrm{~kg} / \mathrm{m}^{2}$ ) for 6 days/wk, with no dietary restrictions.

Results. Mean exercise peak occurred at higher intensity in controls $(140$ vs. $110 \mathrm{~W}, \mathrm{p}<0.05)$ and AT exceeded at higher work outputs than in obese subjects (102 vs. $74 \mathrm{~W}, \mathrm{p}<0.05)$. In controls, GH response to exercise was prompt and further sustained after AT; in obese subjects, GH increased slowly and unsignificantly before AT, thereafter it increased to lower levels than in controls $(\mathrm{p}<0.001)$. Following the reconditioning period, both Group A and Group B of obese subjects failed to improve exercise performance as well as $\mathrm{GH}$ response to exercise before AT; beyond AT, a greater GH response to exercise occurred in Group B than Group A $(7.59 \pm 0.32 \mu \mathrm{g} / \mathrm{l}$ at peak of exercise) with significantly different Delta AUCs following AT: $30.5 \pm 12 \mu \mathrm{g}$-min/l in the Group A vs $124.2 \pm 38 \mu \mathrm{g}-\mathrm{min} / \mathrm{l}$ in the Group B, p $<0.05$. 
Conclusions. Our results confirm the blunted GH response to exercise in obese adults when compared to lean counterparts. With obesity, aerobic training poorly increases the GH response beyond AT while supplemental anaerobic workload appears to increase GH response beyond AT. These observations may have implications for prescription of physical exercise, which is one of the recommendations in the management of obesity.

\section{Introduction}

$\mathrm{GH}$ is one of the key regulators of body fat and lean tissue. Its pulsatile secretion is positively governed by GHRH and inhibited by somatostatin (1). A variety of physiological and pathological conditions are known to affect GH secretion. They include age, gender, pubertal stage, sleep, nutritional status, body composition and temperature, fitness, gonadal steroids, insulin and $\operatorname{IGF-I}(1,2,3)$.

GH secretion is responsive to bouts of physical activity (4) by an order of magnitude that depends on exercise intensity and duration, fitness and age (5). Several Authors suggested that GH response implies a threshold of exercise intensity, while others have documented that GH secretion increases linearly with increasing intensity of exercise $(6,7)$.

Body fat and aerobic fitness act to control GH secretion with an inverse relationship existing between relative abdominal fat and $\mathrm{VO}_{2}$ peak, as well as with the 24-h integrated $\mathrm{GH}$ concentrations $(2,3)$. It is well known that abdominal visceral fat increases in obese subjects and this has been claimed to explain why obesity dramatically reduces spontaneous and stimulated GH secretion $(1,2)$, decreases the $24 \mathrm{~h}$ GH secretory bursts and accelerates GH disposal rates (8), supposedly due to a diminished GHRH or increased somatostatin tone (1).

Importantly, obesity blunts the GH response to exercise (2).

The American College of Sport Medicine recommends the addition of resistance exercise to a program of regular aerobic training (9) and only a few studies assessed the effect of concurrent strength and endurance training on GH (4), particularly in obese subjects. 
In the present study we thought to examine the dynamics of acute GH secretion in a group of adult obese and control subjects during a progressive cycloergometric test up to the maximal work capacity and, subsequently, to evaluate the GH response to the same exercise protocol in obese subjects following a 4-wk training period by aerobic or by aerobic plus anaerobic daily exercise, without diet restrictions.

\section{Subjects and experimental protocol}

The protocol was approved by the Ethics Review Committee of our Institution and written informed consent was given by all the subjects before participation, in accordance with the Helsinki Declaration (1964, amended in 1975 and 1983) of the World Health Organization.

The obese group consisted of 16 subjects (7 males; age 39.1 yrs, range 20-59 yrs, BMI 35.8 $\mathrm{kg} / \mathrm{m}^{2}$, range 30-42) while 8 untrained lean subjects (4 males; age 34.3 yrs, range 26-47 yrs; BMI $22.1 \mathrm{~kg} / \mathrm{m}^{2}$, range 17-25) served as controls (Tab. 1A). Exclusion criteria were smoking, physical inability, hypertensive, diabetic or suffering from any other cardiovascular or metabolic disorders. Physical examination, EKG, routine blood and urine analysis were carried out preliminarily to exclude medical illnesses. Women were analysed during early follicular phase of the menstrual cycle. The study protocol included anthropometric measurements after voiding and bioimpedence analysis (BIA 101/S Akern, Florence, Italy) for measurement of fat (FM, kg) and fat-free mass (FFM, kg). Patients with fluid overload according to vectorial analysis were excluded to minimise errors in estimating FM and LBM in severe obesity. BMI was calculated as weight $(\mathrm{kg}) / \mathrm{height}\left(\mathrm{m}^{2}\right)$.

Before exercise testing, subjects were asked to restrain from strenuous activity for at least 24 h. In each subject a preliminary nocturnal $\mathrm{O}_{2}$ saturation monitoring did not demonstrate the presence of significant periods of pathological low values. Following an overnight fasting, at 8 am individuals underwent an ergospirometric test in a thermo-regulated room on a bicycle ergometer at a pre-set pedalling rate of $60 \mathrm{cycle} / \mathrm{min}$ and initial workload of 20 watt. Exercise intensity was subsequently increased by 20 -watt steps every 4 min until physical exhaustion occurred. Subjects 
were vocally encouraged to maintain a constant speed while the wheel resistance level was adjusted to preserve an increasing power output. At the beginning of recovery, subjects were invited to cycle for 2 more min effortlessly, and then were followed for up to 40 min while maintaining a sitting position. For analytical purposes, sampling was performed through an indwelling cannula inserted at the antecubital vein and kept patent by continuous slow saline infusion. Blood was sampled at baseline, during the last $30 \mathrm{~s}$ of each power output increase, and at first recovery (5 min) and late recovery (30 $\mathrm{min})$.

A cardiopulmonary exercise test station (Vmax 229, Sensor Medics, Yorba Linda, CA, USA) was used for continuous analysis of oxygen consumption $\left(\mathrm{VO}_{2}\right), \mathrm{CO}_{2}$ production $\left(\mathrm{VCO}_{2}\right)$ and minute ventilation (VE). Exercise capacity was assessed by determining the maximum work rate, ventilatory anaerobic threshold (AT), and $\mathrm{VO}_{2}$-max defined as the $\mathrm{VO}_{2}$ averaged over the last minute of exercise. AT was detected by the V-slope method (10). Calibrations were performed prior to each test. Heart rate (HR) and EKG signals were recorded by a CASE 6.5 (GE Medical System Milwaukee, WI, USA) and oxyhaemoglobin saturation was determined by a Radiometer percutaneous oxymeter. Blood haemoglobin was determined in all subjects at baseline.

\section{Exercise training}

Following the baseline evaluation, in-patient obese subjects were randomly assigned to 2 subgroups each comprising 8 subjects matched by gender, age and BMI (Group A: 3 males and 5 females; age 40.5 yrs, range 22-59 yrs; BMI $33.6 \mathrm{~kg} / \mathrm{m}^{2}$, range 30-41; Fat mass $36.5 \mathrm{~kg}$; Fat-free mass $52 \mathrm{~kg}$; Group B: 4 males and 4 females; age 37.6 yrs, range 20-56 yrs, BMI $38.0 \mathrm{~kg} / \mathrm{m}^{2}$, range 34-42; Fat mass $48.1 \mathrm{~kg}$; Fat-free mass $68.9 \mathrm{~kg}$ ). Group B differed from Group A in a higher Fat mass $(\mathrm{p}<0.05)$. Each subgroup underwent a 4-wk training protocol consisting of 2-daily 30 min cycloergometric exercise sessions for 6 days/wk. In Group A, the power output of each training session was exclusively aerobic, constantly attaining $70 \%$ of HR registered at AT. In Group B, the power output of each training session was aerobic (25 $\mathrm{min})$ and anaerobic $(5 \mathrm{~min})$, attaining $70 \%$ of 
the HR registered at AT for the aerobic part, and $85 \%$ of the maximal HR for the anaerobic part. Increments of power output were imposed in view of the actual improvement by reconditioning, maintaining HR 70\% of AT (Group A and B) and 85\% (Group B) as the reference standards. Oxygen saturation and heart rate were continuously monitored during each training session. At the end of each training period, each of the participants in Group A and Group B underwent a conclusive ergospirometric test according to the same protocol setting as the entry test.

\section{Hormone measurements}

GH levels were measured by chemioluminescence (Immulite 2000 Analyser, DPC, Los Angeles, CA) calibrated against WHO $1^{\text {st }}$ IRP $80 / 50$, having a sensitivity of $0.01 \mu \mathrm{g} / 1$ and intra- and inter-assay coefficients of variation (CVs) of 2.9-4.2\% and 4.2-6.5\%, respectively.

\section{Statistical analysis}

In controls and obese subjects all the values obtained at each step of the test were compared between groups by analysis of variance (ANOVA), transforming data to the natural logarithmic scale when requested (11). Among obese subjects and controls, integrated GH concentrations (area under the curve) were calculated during exercise and recovery by using the trapezoidal rule (12). ANOVA was employed to determine differences between groups and between pre and post training values.

\section{Results}

Exercise testing at study entry

Control subjects reached a mean maximal peak of exercise at $140 \pm 12 \mathrm{~W}$ and exceeded AT at a mean value of $102 \pm 11 \mathrm{~W}$ (Tab.1 A). $\mathrm{VO}_{2} \max$ was $1860 \mathrm{~mL} / \mathrm{min}(28.52 \mathrm{~mL} / \mathrm{Kg} / \mathrm{min}, 81 \%$ of theoretical maximal $\left.\mathrm{VO}_{2}\right)(13,14)$. The obese subjects, on the whole (Tab. 1), reached a mean 


\section{Effects of a 4-wk aerobic training in obesity}

At study entry, Group A achieved a mean exercise peak of $92.5 \pm 9 \mathrm{~W}$ ( $\mathrm{p}<0.01$ vs controls) and exceeded AT at $64 \pm 6 \mathrm{~W}$ (p<0.01 vs controls). $\mathrm{VO}_{2}$ max was $1625 \mathrm{~mL} / \mathrm{min}(18.37 \mathrm{~mL} / \mathrm{Kg} / \mathrm{min}$, $79 \%$ of theoretical $\left.\mathrm{VO}_{2} \max \right)$. At the end of the 4-wk aerobic training period, mean exercise peak at exhaustion and AT unsignificantly rose to $110 \pm 10 \mathrm{~W}$ and $74 \pm 6 \mathrm{~W}$, respectively. $\mathrm{VO}_{2} \max$ increased to $1720 \mathrm{~mL} / \mathrm{min}\left(20.25 \mathrm{~mL} / \mathrm{Kg} / \mathrm{min}, 81 \%\right.$ of theoretical $\mathrm{VO}_{2}$ max $)$. During this period, body weight and composition did not change significantly in any patient.

GH response to exercise was null before AT while it increased at the peak exercise $(p<0.01$ vs rest, $\mathrm{p}<0.05$ vs AT) and persisted at higher levels than baseline at the first recovery, decreasing thereafter (Fig. $1 \mathrm{~B}$ ). The 4-wk aerobic training reconditioning program did not impact the pattern of GH secretion, which only significantly increased at the peak exercise $(\mathrm{p}<0.01$ vs rest, $\mathrm{p}<0.05$ vs AT), then decreasing during the late recovery (Fig. 1 B). GH values before and after the training period were similar at any time point.

As shown in Fig. 1A, Group A achieved lower GH response to exercise than controls both at study entry and after the training period at AT ( $\mathrm{p}<0.01$ and $\mathrm{p}<0.05$, respectively), peak exercise $(\mathrm{p}<0.01$ and $\mathrm{p}<0.05$, respectively), first recovery $(\mathrm{p}<0.01$ for both) and late recovery $(\mathrm{p}<0.001$ and $\mathrm{p}<0.05$, respectively). 


\section{Effects of a 4-wk aerobic plus anaerobic training in obesity}

At study entry, Group B reached a mean peak at exhaustion at $127 \mathrm{~W} \pm 9$ ( $\mathrm{p}=\mathrm{NS}$ vs controls) and exceeded AT at a mean value of $85 \pm 7 \mathrm{~W}\left(\mathrm{p}=\mathrm{NS}\right.$ vs controls). $\mathrm{VO}_{2}$ max was 2080 $\mathrm{mL} / \mathrm{min}\left(17.89 \mathrm{~mL} / \mathrm{Kg} / \mathrm{min}, 75 \%\right.$ of theoretical $\left.\mathrm{VO}_{2} \max \right)$. At the end of the aerobic and anaerobic training period, the mean peak at exhaustion rose up to $140 \pm 10 \mathrm{~W}$ and AT up to $97 \pm 8 \mathrm{~W}$ ( $\mathrm{p}=\mathrm{NS}$ vs starting values). $\mathrm{VO}_{2}$ max increased to $2165 \mathrm{~mL} / \mathrm{min}\left(19.60 \mathrm{~mL} / \mathrm{Kg} / \mathrm{min}, 77 \%\right.$ of theoretical $\mathrm{VO}_{2}$ max). Similarly to Group A, weight and fat mass did not change significantly with training.

Exercise failed to evoke any significant GH response at AT, while this occurred at the peak exercise ( $<<0.05$ vs rest, $p<0.05$ vs AT), persisted during the first recovery and decreased following (Fig. 1 B). At the end of the 4-wk aerobic plus anaerobic training program, GH response was weak at AT and became significant at the peak exercise ( $\mathrm{p}<0.05$ vs rest, $\mathrm{p}<0.05$ vs AT), persisted at the first recovery and decreased at the late recovery (Fig. 1 B). Like in Group A, no significant difference occurred in $\mathrm{GH}$ values before and after the training period.

As shown in Fig. 1 B, GH was less responsive to exercise in Group B than controls before the training period at AT $(\mathrm{p}<0.05)$, peak exercise $(\mathrm{p}<0.01)$, first recovery $(\mathrm{p}<0.01)$ and late recovery $(\mathrm{p}<0.01)$. Unlike Group A, however, the combination aerobic plus anaerobic training program abrogated the previously documented differences in GH response to exercise between Group B and controls at any time but late recovery $(\mathrm{p}<0.01)$ (Fig. 1 B).

\section{Comparison between different training programs}

Improvements in physical performances, albeit not significant, were obtained in any obese subjects after either training periods. When GH results were normalised according to power output achieved at AT $\left(\mathrm{GH} / \mathrm{W}_{\mathrm{AT}}\right)$ and peak exercise $\left(\mathrm{GH} / \mathrm{W}_{\mathrm{PE}}\right)$, both Group A and Group B showed significantly lower $\mathrm{GH} / \mathrm{W}_{\mathrm{AT}}$ and $\mathrm{GH} / \mathrm{W}_{\mathrm{PE}}$ values before training than controls. In normal subjects $\mathrm{GH} / \mathrm{W}_{\mathrm{AT}}$ and $\mathrm{GH} / \mathrm{W}_{\mathrm{PE}}$ were $0.098 \pm 0.035$ and $0.117 \pm 0.039 \mu \mathrm{g} / \mathrm{l} /$ watts respectively; in Group A, pre-training $\mathrm{GH} / \mathrm{W}_{\mathrm{AT}}$ and $\mathrm{GH} / \mathrm{W}_{\mathrm{PE}}$ were, respectively, $0.028 \pm 0.012$ and $0.037 \pm 0.010 \mu \mathrm{g} / \mathrm{l} / \mathrm{watts}$ 


\section{Discussion}

The stimulating effect of acute exercise on $\mathrm{GH}$ secretion has been extensively documented in non obese individuals (15). To our knowledge, no study has so far examined the effect of prospective exercise training on the GH response to acute exercise in obesity. Exercise is one of the most potent physiological stimuli to GH release. Oppositely, obesity dampens GH bursts caused by exercise, although the underlying mechanisms for this dysfunction are largely undetermined $(1,4)$. Our study sought to evaluate in obese subjects if aerobic, or aerobic plus anaerobic training could elicit a dichotomised response of GH to acute exercise. In agreement with previous studies (16), obese subjects achieved a reduced work capacity when compared to controls. Our data also confirm the known significant differences in GH response to exercise between obese and normal subjects. The latter, in fact, exhibited a greater post-training $\mathrm{GH}$ increment, which appeared to be steeper particularly beyond AT and persisted elevated at the peak exercise as well as during the whole recovery period. Pritzlaff et al. (17), found in young men and young women that the magnitude of GH release augmented linearly with increasing intensity of exercise. Our results in adult normal subjects thus seem to agree with a linear correlation existing between $\mathrm{GH}$ and increasing work 
outputs up to AT. Beyond AT, the increase seemed to be faster, according with the notion that resistance exercise protocols result in the greatest GH response (18). At variance with these results, obese individuals achieved a weak GH response before AT despite a clear-cut increase in the power output and, thereafter, the increase in GH levels failed to reach a magnitude similar to that obtained in control subjects. While it's known that GH secretion increases with obesity at a lower magnitude than in the lean state (1), our findings support the hypothesis that GH response to exercise in obesity is unrelated to exercise intensity before $\mathrm{AT}$, while a measurable GH response could be documented following AT. A dose-response relationship thus appears to exist between exercise intensity and GH responsiveness in obesity after AT. Therefore, exceeding AT seems to act as a point for the modification in the GH response to exercise in obesity. The difference seen in the GH response seems authentic, as it also persisted when adjusted for external work rates, to correct for potential differences in physical performance among the different subgroups.

Noticeably, GH levels appeared to be sustained in the post-exercise recovery period in controls, while in both obese groups GH levels returned rapidly to starting values. We speculate that this circumstance might confirm previous evidence of a decreased GH half-life (17), or an increased rate of disposal during exercise occurring with obesity by an increased clearance $(1,8)$.

One main finding of our study resides, however, in the differential effects of a 4-wk exercise training comprising aerobic alone or aerobic plus anaerobic training on GH response to acute exercise. Training did not appear to change GH concentrations at rest and before AT significantly in either group. When expressed as areas under the curve, however, we documented that the obese group subjected to supplemental anaerobic training achieved greater GH increments beyond AT than in solo aerobic-trained subjects. A concomitant improvement in physical performance, though statistically not significant, was observed in both groups at the end of the training period, consisting in higher work rates at AT and greater maximal sustainable work capacity. It is difficult to discriminate if post-training change in $\mathrm{GH}$ response to exercise occurred as a function of anaerobic 
training or was simply due to a more intense training. Anaerobic training might reduce abdominal visceral fat, and thus GH clearance.

Contrary to previous studies, we found no between-gender differences in the post-exercise dynamics of GH increase possibly due to a limited number of participants tested. On the other hand, a recent report has noted no difference between genders in older adults (19).

Some additional caveats should be considered in the interpretation of our results. Firstly, aerobic fitness may influence GH release via effects on abdominal visceral fat and fasting insulin concentrations (5). While we categorised obesity based on BMI values, a greater amount of visceral fat may per se attenuate $\mathrm{GH}$ release more than overall obesity $(1,20)$. In line with this inference, administration of rh-GH to obese adults has been shown to reduce visceral more than cutaneous abdominal fat $(21,22)$. Thus, exercise training at an appropriate intensity should elevate GH release (19) and reduce visceral abdominal fat. Secondly, the short length of the training periods may have limited the significance of our observations. Being our aim to look for differences between aerobic and anaerobic work, we wanted to make sure that the appropriate aerobic and anaerobic workloads were carried out. So we enrolled exclusively obese in-patients, and the training period could thus not be longer than four weeks. Again, each exercise was performed in the same thermo-regulated room, but we had no core temperature before and after the test. Differences of it may condition absolute GH levels (23). Group B had a significantly higher fat mass than Group A, nevertheless we may suppose that this difference had little or no influence on GH response to training; its levels before training were similar to those of Group A.

In summary, single bouts of exercise seem to evoke a measurable GH responsiveness in obesity only when exercise intensity overpowers AT. This also occurs after a short training period. However, training intensity plays a key role in determining the magnitude of GH response, that is: higher the intensity, higher the response. As such, a training program consisting of aerobic and anaerobic workout may contribute to normalise GH responsiveness to exercise after AT in obese subjects. 
Attenuation of GH responses in obesity at all exercise intensities, especially those below AT, should have implications for the application of exercise as a prescription, and higher exercise intensities might be required to stimulate an adequate $\mathrm{GH}$ release. Likely, studies in larger obese cohorts and following longer training are warranted to confirm and expand current results. 


\section{References}

1) Kanaley, J.A., Weatherup-Dentes, M.M., Jaynes, E.B., Hartman, M.L. (1999) Obesity attenuates the growth hormone response to exercise. J Clin Endocrinol Metab, 84, 3156-3161.

2) Veldhuis, J.D., Liem, A.Y., South, S., Weltman, A., Weltman, J., Clemmons, D.A., Abbott, R., Mulligan, T., Johnson, M.L., Pincus, S. (1995) Differential impact of age, sex steroid hormones, and obesity on basal versus pulsatile growth hormonesecretion in men as assessed in an ultrasensitive chemiluminescence assay. J Clin Endocrinol Metab, 80, 3209-3222.

3) Weltman, A., Weltman, J.Y., Hartman, M.L., Abbott, R.D., Rogol, A.D., Evans, W.S., Veldhuis, J.D. (1994) Relationship between age, percentage body fat, fitness, and 24-hour growth hormone release in healthy young adults: effects of gender. J Clin Endocrinol Metab, 78, 543-548.

4) Felsing, N.E., Brasel, J.A., Cooper, D.M. (1992) Effect of low and high intensity exercise on circulating growth hormone in men. J Clin Endocrinol Metab, 75, 157-162.

5) Eliakim, A., Scheet, T.P., Newcomb, R., Mohan, S., Cooper, D.M. (2001) Fitmess, training and the growth hormone-insulin-like growth factor I axis in prepubertal girls. J Clin Endocrinol Metab, 86, 2797-2802.

6) Wideman, L., Weltman, J.Y., Hartman, M.L., Veldhuis, J.D., Weltman, A. (2002) Growth hormone release during acute and chronic aerobic and resistance exercise. Sports Med, 32(15), 987-1004.

7) Lassarre, C., Girard, F., Durand, J., Raynaud, J. (1974) Kinetics of human growth hormone during submaximal exercise. J Appl Physiol, 37, 826-830.

8) Veldhuis, J.D., Sotos, J.F., Sherman, B.M. (1991) Decreased metabolic clearance of endogenous growth hormone and specific alterations in the pulsatile mode of growth hormone secretion occur in prepuberal girls with Turner's syndrome. Genentech Collaborative Group. J Clin Endocrinol Metab, 73, 1073-1080. 
9) American Medicine College of Sport Medicine (2000). ACSM's guidelines for exercise testing and prescription. $6^{\text {th }}$ ed. Baltimore (MD): Lippincott Williams \& Wilkins.

10) Beaver, W.L., Wasserman, K., Whipp, B.J. (1986) A new method for detecting anaerobic threshold by gas exchange. J Appl Physiol, 60, 2020-2027.

11) Steel, R.G.D., Torrie, J.H. (1980) Principles and procedures of statistics, a biometrical approach. New York, Mc Graw-Hill, pp 188-190.

12) Rowland, M., Tozer, T.N. (1995) Clinical Pharmacokinetics: Concepts and clinical applications. Media, Williams \& Wilkins, 3rd ed., pp 469-472.

13) Bruce, R.A., Kusumi, F., Hosmer, D. (1973) Maximal oxygen uptake and nomographic assessment of functional aerobic impairment in cardiovascular disease. Am Heart J, 85, 546562.

14) Hansen, J.E., Sue, D.Y., Wasserman, K. (1984) Predicted values for clinical exercise testing. Am Rev Respir Dis, 129 (suppl), S49-S55.

15) Weltman, A., Weltman, J.Y., Schurrer, R., Evans, W.S., Velhuis, J.D., Rogol, A.D. (1992) Endurance training amplifies the pulsatile release of growth hormone: effects of training intensity. J Appl Physiol, 72, 2188-2196.

16) Salvadori, A., Fanari, P., Mazza, P., Agosti, R., Longhini E. (1992) Work capacity and cardiopulmonary adaptation of the obese subject during exercise testing. Chest,101, 674-679.

17) Pritzlaff-Roy, C.J., Wideman, L., Weltman, J.Y., Abbot, R., Gutgesell, M., Hartman, M.L., Veldhuis, J.D., Weltman, A. (2002) Gender governs the relationship between exercise intensity and growth hormone (GH) release. J Appl Physiol, 92, 2053-2060.

18) Pritzlaff-Roy, C.J., Wideman, L., Weltman, J.Y., Abbot, R.D., Gutgesell, M.E., Hartman, M.L., Veldhuis, J.D., Weltman, A. (1999) Impact of acute exercise intensity on pulsatile growth hormone (GH) release in men. J Appl Physiol, 87 (2), 498-504. 
19) Weltman , A., Weltman , J.Y., Pritzlaff-Roy, C., Wideman, L., Patrie, J., Evans, W.S., Veldhuis, J.D. (2006) Growth hormone response to graded exercise intensities is attenuated and the gender difference abolished in older adults. J Appl Physiol, 100, 1623-1629

20) Vahl, N., Jorgensen, J.O., Skjaerback, C., Veldhuis, J.D., Orskov, H., Christiansen, J. (1997) Abdominal obesity rather than age and sex predicts the mass and patterned regularity of growth hormone secretion in mid-life healthy adults. Am J Physiol, 272, E1108-E1116.

21) Johannsson, G., Marin, P., Lonn, L., Ottosson, M., Stenlof, K., Bjorntorp, P., Sjostrom, L., Bengtsson, B.A. (1997) Growth hormone treatment of abdominally obese men reduces abdominal fat mass, improves glucose and lipoprotein metabolism, and reduces diastolic blood pressure. J Clin Endocrinol Metab, 82,: 727-734.

22) Franco, C., Brandberg, J., Lonn, L., Andersson, B., Bengtsson, B.A., Johannsson, G. (2005) Growth hormone treatment reduces abdominal visceral fat in postmenopausal women with abdominal obesity: a 12-month placebo-controlled trial. J Clin Endocrinol Metab, 90, 14661474.

23) Christensen, S.E., Jorgensen, O.L., Moller, N., Orskov, H. (1984) Characterization of growth hormone release in response to external heating. Acta Endocrinol, 107, 295-301. 


\section{Figure's captions:}

Fig. $1 \mathrm{GH}$ in the obese subjects during and after exercise testing before and after the period of training. Group A: aerobic training (N. 8 subjects), Group B: aerobic plus anaerobic training (N. 8 subjects). Asterisks indicate a significant difference before and after the training period in obese subjects vs controls (see the text) $(* \mathrm{p}<0.05, * * \mathrm{p}<0.01)$. \# significant difference after training in obese subjects vs controls (\# p<0.05).

Fig. 2 Histograms represents AUC within AT and late recovery, before and after the training periods, in Group A and Group B of the obese subjects. (see the text). 
Table 1 A. Anthropometric and functional data of the samples

No. of subjects

Sex, M/F

Age (years) ${ }^{b}$

Weight $(\mathrm{Kg})^{\mathrm{b}}$

Height $(\mathrm{cm})^{\mathrm{b}}$

$\operatorname{BMI}\left(\mathrm{Kg} / \mathrm{m}^{2}\right)^{\mathrm{b}}$

Fat-free mass $(\mathrm{Kg})^{\mathrm{b}}$

Fat mass $(\mathrm{Kg})^{\mathrm{b}}$

Exercise at exhaustion (watts) $^{\mathrm{b}}$

AT (watts) ${ }^{\mathrm{b}}$

$\operatorname{Max} \mathrm{VO}_{2}(\mathrm{ml} / \mathrm{min})^{\mathrm{b}}$

${ }^{\mathrm{b}}$ Values are mean $\pm \mathrm{SEM}$. =Maximum $\mathrm{VO}_{2}$

Obese patients

P Value $^{\mathrm{a}}$

Normal subjects

8

$4 / 4$

$34.3 \pm 2.8$

$65.2 \pm 5.3$

$171 \pm 3.4$

$22.1 \pm 1.2$

$50.0 \pm 4.1$

$15.6 \pm 3.4$

$140 \pm 12$
16

\begin{tabular}{cl}
$7 / 9$ & $\mathrm{NS}$ \\
$39.1 \pm 2.9$ & $\mathrm{NS}$ \\
$102.7 \pm 5.8$ & $<0.001$ \\
$168 \pm 3.3$ & $\mathrm{NS}$ \\
$35.8 \pm 1.1$ & $<0.001$ \\
$60.4 \pm 4.2$ & $<0.01$ \\
$42.3 \pm 2.6$ & $<0.01$ \\
$110 \pm 8$ & $<0.05$ \\
$74 \pm 5$ & \\
$1850 \pm 90$ & $<0.02$ \\
$(77 \%$ pred $)$ & $\mathrm{NS}$ \\
\hline
\end{tabular}

Table 1 B. Serum GH concentration $(\mu \mathrm{g} / \mathrm{l})$ during and after exercise testing

\begin{tabular}{lccc} 
Rest $^{\mathrm{b}}$ & $1.83 \pm 0.19$ & $1.08 \pm 0.08$ & NS \\
Free $^{\mathrm{b}}$ & $4.67 \pm 0.30$ & $1.36 \pm 0.09$ & $\mathrm{NS}$ \\
20 watts $^{\mathrm{b}}$ & $5.00 \pm 0.31$ & $1.59 \pm 0.09$ & $\mathrm{NS}$ \\
40 watts $^{\mathrm{b}}$ & $5.44 \pm 0.32$ & $1.53 \pm 0.08$ & $\mathrm{NS}$ \\
60 watts $^{\mathrm{b}}$ & $6.13 \pm 0.33$ & $1.95 \pm 0.09$ & $\mathrm{NS}$ \\
Anaerobic Threshold $^{\mathrm{b}}$ & $9.68 \pm 0.35$ & $2.03 \pm 0.09$ & $<0.01$ \\
Peak $^{\mathrm{b}}$ & $16.38 \pm 0.45$ & $3.66 \pm 0.10$ & $<0.001$ \\
Recovery 1 (5 minutes) $^{\mathrm{b}}$ & $16.69 \pm 0.41$ & $3.99 \pm 0.10$ & $<0.001$ \\
Recovery 2 (30 minutes) $^{\mathrm{b}}$ & $8.36 \pm 0.27$ & $2.10 \pm 0.07$ & $<0.001$ \\
\hline
\end{tabular}

${ }^{\mathrm{a}}$ By two tailed analysis of variance.

Abbreviations: $\quad \mathrm{BMI}=$ body mass index; $\mathrm{AT}=$ anaerobic threshold; $\mathrm{Max} . \mathrm{VO}_{2}$ 

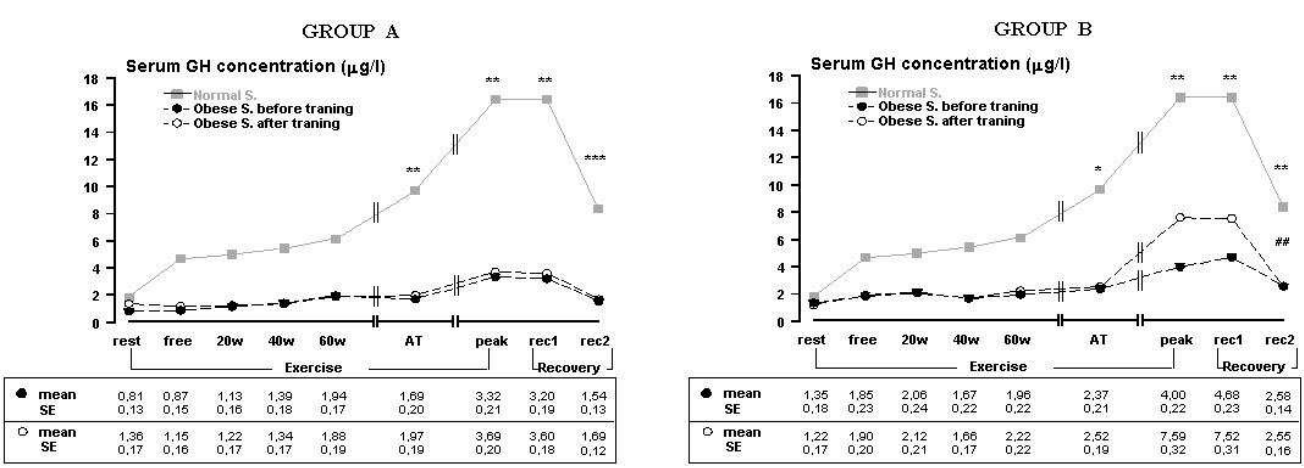

Fig. $1 \mathrm{GH}$ in the obese subjects during and after exercise testing before and after the period of training. Group A: aerobic training (N. 8 subjects), Group B: aerobic plus anaerobic training (N. 8 subjects). Asterisks indicate a significant difference before and after the training period in obese subjects vs controls (see the text) $(* \mathrm{p}<0.05, * * \mathrm{p}<0.01)$. \# significant difference after training in obese subjects vs controlls $(\# \mathrm{p}<0.05)$. $90 \times 31 \mathrm{~mm}(300 \times 300$ DPI $)$ 


1
2
3
4
5
6
7
8
9
10
11
12
13
14
15
16
17
18
19
20
21
22
23
24
25
26
27
28
29
30
31
32
33
34
35
36
37
38
39
40
41
42
43
44
45
46
47
48
49
50
51
52
53
54
55
56
57
58
60

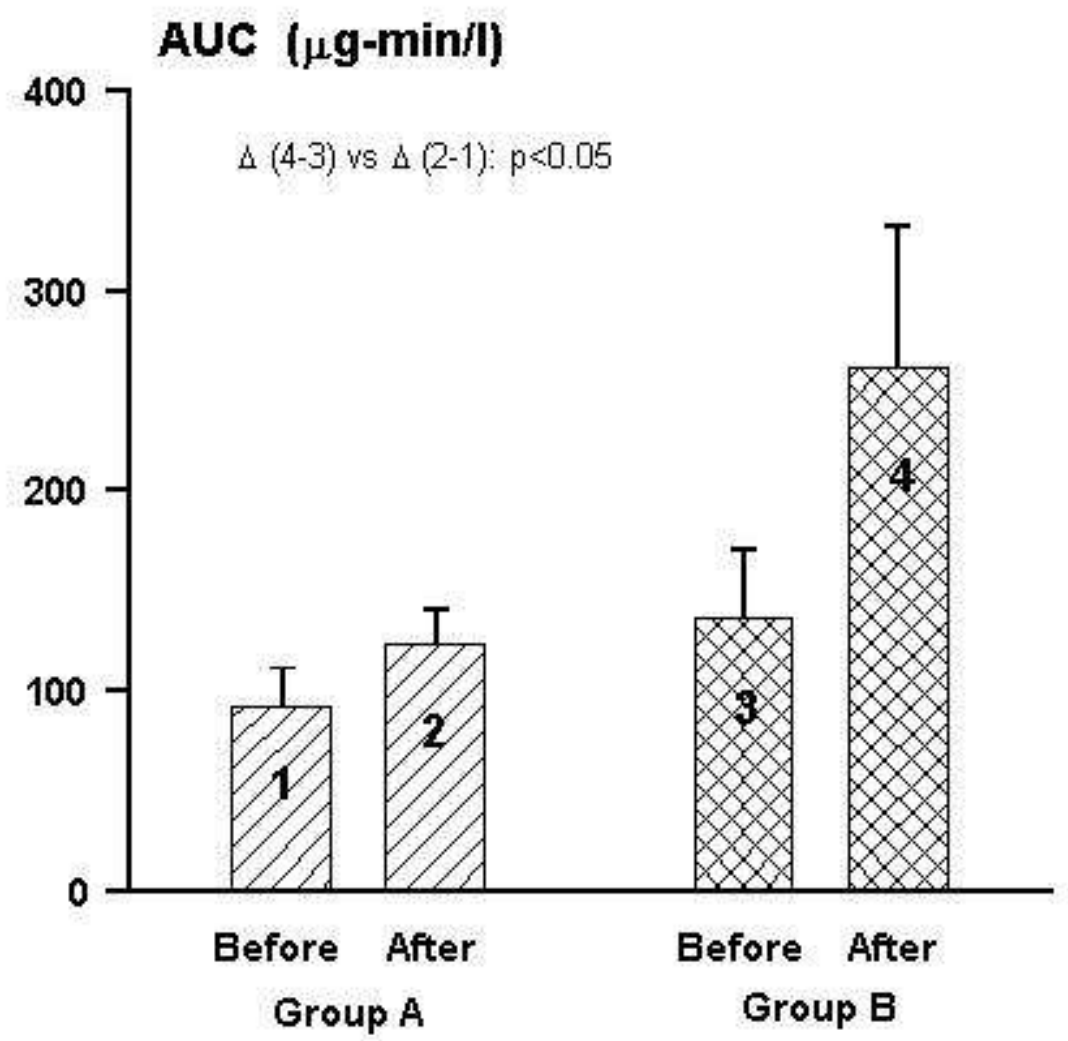

Fig. 2 Histograms represents AUC within AT and late recovery, before and after the training periods, in Group A and Group B of the obese subjects. (see the text). $75 \times 72 \mathrm{~mm}(150 \times 150 \mathrm{DPI})$ 